\title{
Application of Actinobacterial and Fungal Morphology on the Design of Operating Strategies in Bioprocess Development
}

\author{
T. Panda* and G.N. Rameshaiah
}

\begin{abstract}
Biochemical Engineering Laboratory, MSB 140 A and MSB 235A, Department of Chemical Engineering Indian Institute of Technology, Madras, Chennai 600036, India
\end{abstract}

\begin{abstract}
Various options in biotechnology have been exercised to produce industrially important metabolites from filamentous organisms. To select a suitable production strategy, the direct and indirect roles of morphological parameters in controlling bioprocess variables are observed. Some progress has been made in quantitation of morphology.Useful correlations have been reported in the literature in this avenue. Of course, some of the models, with proper modification, can be used to explain the morphological phenomena. This review is concerned with the application of morphological variables to correlate with bioprocess parameters for explaining optimal production strategy.
\end{abstract}

\section{INTRODUCTION}

Fungi and actinobacteria are morphologically complex organisms differing in structure at different times in their life cycle, whether cultured in surface or in submerged growth. The morphology of these organisms plays a critical role in industrial biotechnology.

One of the most studied processes with filamentous microorganisms is penicillin $\mathrm{G}$ production by Penicillium $\mathrm{sp}$. [1]. The complex models of cellular differentiation have limited potential for application in automatic control systems for industrial processes. For this purpose, the study of engineering aspects such as mixing, aeration, and reactor design in relation to growth, morphology, and productivity is necessary. Biochemical engineers are trying to elucidate the interdependence of rheological properties attributed to filamentous growth in fermented broths and transport phenomena related to bioreactor performance to optimize operating conditions in bioreactors for process improvement. Mycelial morphology, metabolite production, and consideration of morphological characteristics are significant avenues in bioprocess design [2].

The fungal fermentation is widely recognized as a complicated multiphase and multi-component process in which numerous problems can occur. Growth of the cultured organism and product formation are determined by a wide range of parameters, including the $\mathrm{pH}$ of the culture medium, the temperature of fermentation, the dissolved oxygen tension in the broth, the shear stress caused by the impeller, and the morphology. Thus, more knowledge on the effects of morphology and operational parameters is required to understand the fermentation process properly and effectively [3].

It is relevant to mention here that Pappagianni [4] reviews on understanding of growth mechanisms of fungal systems

*Address correspondence to this author at the Biochemical Engineering Laboratory, MSB $140 \mathrm{~A}$ and MSB 235A, Indian Institute of Technology, Madras, Chennai 600036, Índia; Tel: +91-9840708563 or +91-4422574160; E-mails: panda@iitm.ac.in or pandaiitm@yahoo.co.in and the factors influencing fungal growth [5] suggested that the understanding of morphology is lagging behind in biopharmaceuticals producing filamentous organisms whereas Grimm et al. [6] hint at the relationship between morphology and productivity as a challenge.

However, the successful production of a fungal metabolite requires a detailed knowledge of the growth characteristics and the physiology of the fungus in question. Each fungus is unique in its anatomical, morphological, and physiological development. So there is a need for suitable correlation between the morphology, the overall growth of the organism, the relevant process variables, and the productivity. This review concentrates on quantitative approaches to morphological parameters and the process variables influencing them to suggest suitable operating strategies for bioprocess development.

\section{QUANTITATION OF FILAMENTOUS ORGANISMS}

\section{Actinobacteria}

Streptomycetes resemble fungi in their structure. Their branching and the filamentous arrangement of cells form a network called the mycelium. In addition to echoing fungi in their cellular structure, Streptomycetes resemble fungi in their elaborate life cycle. During the vegetative growth stage of development, DNA replication takes place without cellular division, creating the previously mentioned filamentous structure. Streptomycetes reproduce and disperse through the formation of spores, called conidia, which follows the period of vegetative growth. The spores are produced in aerial filaments (sporophores), which rise above the colony.The morphology of Streptomyces olindensis was differentiated into four classes: pellets, clumps, branched, and unbranched free filaments by image analysis [7].

\section{Fungi}

Fungi present many levels of epigenetic regulation that lead to morphological variations [8]. A comparative study 
reveals various methods of cell disintegration with reference to efficacy [9] as a wide range of morphological differences exists within the large group of filamentous fungi (Fig. 1) to evaluate morphological parameters. To quantify such variation, one might look for the estimation of various parameters related to the morphology that might be correlated to process parameters.

\section{PARAMETERS INVOLVED IN FUNGAL MOR- PHOLOGY}

Morphology is quantified by the estimation of geometrical characteristics of individual filamentous mycelia represented as hyphae, and spherical colonies called pellets (cf. Table 1). One needs to obtain the exact mechanism of pellet formatiom.

Hyphal geometry can be understood by the values of main hyphal length, equivalent hyphal length, mean hyphal growth unit, 'hair length', total hyphal length, hyphal fragmentation rate, average number of branch points, hyphal diameter, effective mean dimensionless length, branching frequency, total number of tips, number density formation, tip extension rate, hyphal polarity, ramification, angle of branching, and direction of branching. The derived parameters are morphology factor (length to diameter ratio of mycelial particles) and ratio of freely dispersed mycelia to pellets.

For pellets, number of pellets, pellets diameter, compactness of pellets, pellet volume fraction, average pellet mean size, roughness of elements, mean projected area of clumps, mean core convex area, mean core area, core circularity, and fullness of annular region are required as morphological parameters to understand the complex mycelial structure. However, direction of branching of freely suspended mycelia and compactness of the pellets are difficult to evaluate experimentally during production.

\section{Hyphal Growth (Individual Filamentous Mycelia)}

Hyphal growth rate, tip formation rate, tip extension rate, and branch formation rate were measured in Mortierella

\section{Fungal morphology}

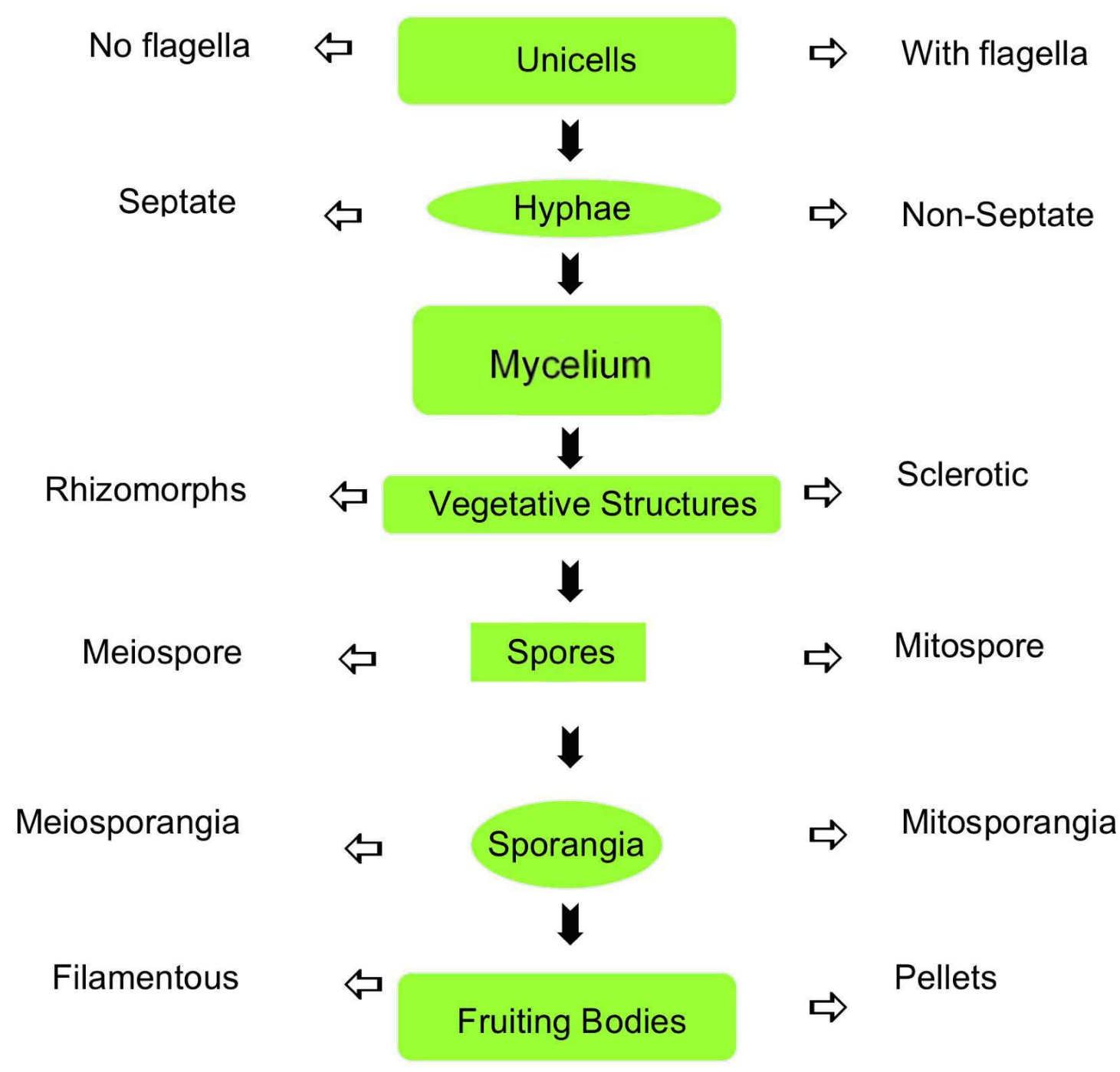

Fig. (1). Schematic representation of fungal morphology. 
Table 1. Parameters Involved in Quantification of Actinobacterial and Fungal Morphology, Correlation to Process Variables and Probable Production Strategy

\begin{tabular}{|c|c|c|c|c|c|}
\hline Aspergillus alutaceus & Petri dish & $\begin{array}{l}\text { Hyphal growth rate, } \\
\text { hyphal length, branch- } \\
\text { ing pattern, hyphal tips, } \\
\text { hyphal extension rate }\end{array}$ & $\begin{array}{l}\text { Ochratoxin production } \\
\text { positively correlated to } \\
\text { branch density, } \mu \text { unal- } \\
\text { tered, no mathematical } \\
\text { relation }\end{array}$ & - & $\begin{array}{c}\text { Blank et al., Lebensm- } \\
\text { Weiss Technol, 31, } 210 \\
\text { (1998) }\end{array}$ \\
\hline Aspergillus awamori & $3 \mathrm{~L}$, Batch & $\begin{array}{l}\text { Hairy length of pellets } \\
\text { at different intensities, } \\
\text { pellet size, pellet } \\
\text { porosity }\end{array}$ & $\begin{array}{l}\text { DOT no effect on myce- } \\
\text { lial fraction, porosity and } \\
\text { pellet size inversely } \\
\text { related to DOT } \\
\text { Quantitative analysis, no } \\
\text { mathematical relation to } \\
\text { productivity }\end{array}$ & - & $\begin{array}{l}\text { Cui et al., Biotechnol } \\
\text { Bioeng, 57, } 409 \text { (1998) }\end{array}$ \\
\hline b) & Agar plates & Hyphal elongation & - & - & $\begin{array}{l}\text { Riquelme } \text { et al., Proto- } \\
\text { plasma, 222, } 211 \text { (2003) }\end{array}$ \\
\hline a) Aspergillus niger & $6 \mathrm{~L}$ & $\begin{array}{l}\text { Equivalent pellet } \\
\text { diameter, clump } \\
\text { roughness }\end{array}$ & Quantitative analysis & $\begin{array}{c}\text { Dispersed mycelia for } \\
\text { high productivity but } \\
\text { causes poor mixing }\end{array}$ & $\begin{array}{l}\text { Paul et al., Biochem Eng J, } \\
\text { 3, } 121 \text { (1999) }\end{array}$ \\
\hline b) & $8 \mathrm{~L}$, Batch, Fed batch, & $\begin{array}{l}\% \text { vacuolated vol. of } \\
\text { filaments, mean diame- } \\
\text { ter of filaments, mean } \\
\text { length of filaments }\end{array}$ & $\begin{array}{l}\text { No mathematical treat- } \\
\text { ment }\end{array}$ & $\begin{array}{c}\% \text { vacuolated fila- } \\
\text { ments more in fed } \\
\text { batch at low reactant } \\
\text { level lower portion of } \\
\text { vacuoles posses } \\
\text { higher } \mu \text { and higher } \\
\text { proportion of shorter } \\
\text { filament having } \\
\text { higher specific } \\
\text { production rate in fed } \\
\text { batch }\end{array}$ & $\begin{array}{c}\text { Pappagianni, Process } \\
\text { Biochem, 35, } 359 \text { (1999) }\end{array}$ \\
\hline c) & $6 \mathrm{~L}$, Batch & $\begin{array}{c}\text { Mean pellet convex } \\
\text { area, Mean core convex } \\
\text { area, mean pellet } \\
\text { equivalent diameter, } \\
\text { Mean core area, core } \\
\text { circularity, fullness of } \\
\text { annular region }\end{array}$ & - & $\begin{array}{l}\text { Partial solution to } \\
\text { scale up }\end{array}$ & $\begin{array}{l}\text { Priede } \text { et al., Food Technol } \\
\text { Biotechnol, 40, } 57 \text { (2002) }\end{array}$ \\
\hline Aspergillus oryzae & $6 \mathrm{~L}$; Batch & $\begin{array}{l}\text { Hyphal tip activity, } \\
\text { mean total hyphal } \\
\text { length, mean projected } \\
\text { area, number of tip per } \\
\text { hypha. }\end{array}$ & Quantitation & $\begin{array}{l}\text { Agitation intensity to } \\
\text { be manipulated to } \\
\text { meet DOT, bulk } \\
\text { mixing, broth rheol- } \\
\text { ogy, mycelial mor- } \\
\text { phology }\end{array}$ & $\begin{array}{c}\text { Amanullah et al., Biotech- } \\
\text { nol Bioeng, 62, } 434 \text { (1999); } \\
77,815 \text { (2002) }\end{array}$ \\
\hline Aspergillus oryzae & $80 \mathrm{~m}^{3}$ batch & $\begin{array}{c}\text { Equivalent hyphal } \\
\text { length, total number of } \\
\text { tips, average number of } \\
\text { branch points, frag- } \\
\text { mentation rate }\end{array}$ & - & - & $\begin{array}{l}\text { Li et al., Biotechnol Bio- } \\
\text { eng, } 77,60(2002)\end{array}$ \\
\hline
\end{tabular}


(Table 1) contd....

\begin{tabular}{|c|c|c|c|c|c|}
\hline Organism & $\begin{array}{c}\text { Fermenter Capacity } \\
\text { and Mode of } \\
\text { Operation }\end{array}$ & Parameter Studied & $\begin{array}{c}\text { Correlation Between } \\
\text { Mycelial Parameter } \\
\text { and Process Parameter }\end{array}$ & Process Strategy & Reference* $^{*}$ \\
\hline Blakeslia trispora & $\begin{array}{c}250 \mathrm{~mL} \text { Erlenmeyer } \\
\text { flask }\end{array}$ & $\begin{array}{l}\text { Microscopic view, no } \\
\text { measurement }\end{array}$ & No & $\begin{array}{l}\text { Dispersed growth in } \\
\text { batch associated with } \\
\text { increased } \\
\beta \text {-carotene synthesis }\end{array}$ & $\begin{array}{l}\text { Jeong et al., Current Mi- } \\
\text { crobiol 42, } 225 \text { (2001) }\end{array}$ \\
\hline $\begin{array}{l}\text { Cephalosporium } \\
\text { acremonium }\end{array}$ & $\begin{array}{l}500 \mathrm{~mL} \text { Erlenmeyer } \\
\text { flask }\end{array}$ & $\begin{array}{l}\text { Hyphae, orthospores, } \\
\text { conidia, germlings }\end{array}$ & - & - & $\begin{array}{l}\text { Nash and Huber, Appl } \\
\text { Microbiol, 22, } 6 \text { (1971) }\end{array}$ \\
\hline Fusarium moniliforme & $6 \mathrm{~L} ;$ Batch & $\begin{array}{l}\text { Main Hyphal length, } \\
\text { Total hyphal length, } \\
\text { Hyphal width, hyphal } \\
\text { growth unit, Hyphal } \\
\text { growth volume, Myce- } \\
\text { lial clump perimeter, } \\
\text { projected area, rough- } \\
\text { ness }\end{array}$ & Quantitation & $\begin{array}{l}\text { Generation of longer } \\
\text { and thinner hyphae } \\
\text { for better productivity }\end{array}$ & $\begin{array}{l}\text { Priede } \text { et al., Biotechnol } \\
\text { Bioeng, 48, } 266 \text { (1995) }\end{array}$ \\
\hline a) Neurospora crassa & $0.5 \mathrm{~L}$; Batch & $\begin{array}{l}\text { Ultrastructural studies } \\
\text { of hyphae }\end{array}$ & - & - & $\begin{array}{c}\text { Lowry et al., J Bacteriol, } \\
94,1757 \text { (1967) }\end{array}$ \\
\hline b) & $\begin{array}{l}\text { Hollow glass tube } \\
\text { for growth }\end{array}$ & $\begin{array}{l}\text { Mycelial elongation, } \\
\text { hyphal tip, nuclei }\end{array}$ & - & - & $\begin{array}{l}\text { Selier et al., EMBO J 16, } \\
3025 \text { (1997) }\end{array}$ \\
\hline a) Penicillium chrysogenum & $0.5 \mathrm{~L}$ to $2 \mathrm{~L} ;$ Batch & $\begin{array}{l}\text { Pellets and filaments, } \\
\text { hyphal and pellet } \\
\text { diameter }\end{array}$ & - & - & $\begin{array}{l}\text { Liu and Yu, Biotechnol } \\
\text { Bioeng, 42, } 777 \text { (1993) }\end{array}$ \\
\hline b) & $2 \mathrm{~L}$ to $100 \mathrm{~L}$; Batch & $\begin{array}{l}\text { Effective hyphal } \\
\text { length, } \\
\text { hyphal growth unit, } \\
\text { total hyphal length, } \\
\text { number of branches }\end{array}$ & $\begin{array}{c}\text { Apparent qualitative } \\
\text { correlation exists be- } \\
\text { tween hyphal length and } \\
\text { penicillin synthesis }\end{array}$ & - & $\begin{array}{l}\text { Smith et al., Biotechnol } \\
\text { Bioeng, 35, } 1011 \text { (1990) }\end{array}$ \\
\hline c) & $\begin{array}{l}2 \mathrm{~L} \text { to } 75 \mathrm{~L} \text {; } \\
\text { Continuous, fed batch }\end{array}$ & $\begin{array}{l}\text { Mean total hyphal } \\
\text { length and mean pro- } \\
\text { jected area., } \mathrm{P} / \mathrm{V}_{\mathrm{L}}\end{array}$ & - & - & $\begin{array}{l}\text { Jüsten } \text { et al., Biotechnol } \\
\text { Bioeng, 52, } 672 \text { (1996) }\end{array}$ \\
\hline d) & Chemostat & $\begin{array}{l}\text { Hyphal growth unit, } \\
\text { hyphal branching } \\
\text { frequency }\end{array}$ & $\begin{array}{l}\text { Empirical relation be- } \\
\text { tween specific growth } \\
\text { and hyphal branching }\end{array}$ & & $\begin{array}{c}\text { Morrison and Righelato, J } \\
\text { Gen Microbiol, 81, } 517 \\
\text { (1974) }\end{array}$ \\
\hline $\begin{array}{c}\text { Phytophthora parasitica, } \\
\text { Neurospora crassa, } \\
\text { Schizophyllum commune }\end{array}$ & & Hyphal growth & - & - & $\begin{array}{c}\text { Hunsley and Burnett, J Gen } \\
\text { Microbiol, 62, } 203 \text { (1970) }\end{array}$ \\
\hline Streptomyces griseus & $6 \mathrm{~L} ;$ Continuous & $\begin{array}{l}\text { Mycelial clump area, } \\
\text { perimeter, compact- } \\
\text { ness, roughness }\end{array}$ & - & - & $\begin{array}{c}\text { Obert et al., J Bacteriol, } \\
172,1180(1990)\end{array}$ \\
\hline Streptomyces clavuligerus & $7 \mathrm{~L}$; Batch, fed batch & $\begin{array}{l}\text { Main hyphal length, } \\
\text { total hyphal length, } \\
\text { number of tips, hyphal } \\
\text { growth unit, }\end{array}$ & - & - & $\begin{array}{c}\text { Belmar-Beiny and Thomas, } \\
\text { Biotechnol Bioeng, } 37,456 \\
\text { (1991) }\end{array}$ \\
\hline Thielaviopsis basicola & Batch & $\begin{array}{l}\text { Hyphal length, diame- } \\
\text { ter, degree of branching }\end{array}$ & - & - & $\begin{array}{l}\text { Hood and Shew, Mycolo- } \\
\text { gia, 89, } 793 \text { (1997) }\end{array}$ \\
\hline $\begin{array}{l}\text { Trichoderma harzianum, } \\
\text { Fusarium culmorum }\end{array}$ & Batch & Fragment length & - & - & $\begin{array}{c}\text { Cheetham et al., J } \\
\text { Microbiol Methods, 21, } \\
113 \text { (1995) }\end{array}$ \\
\hline
\end{tabular}

* For space limitation, details of references are not given in reference list. 
alpina growing on 25 different combinations of carbon and nitrogen concentrations using a flow-through chamber. Experimental conditions were developed such as various nutrient concentrations having five defined $\mathrm{C} / \mathrm{N}$ ratios to examine hyphal morphology. This system can be used to evaluate both morphological development and morphological parameters [10]. Chitinase and $\beta$-1,3-glucanase were used to study hyphal in vitro growth of Glomus mosseae. Chitinase applied to the hyphal tip inhibits hyphal extension and lysis of apex and alterations in the growth pattern. Chitinase or glucanase does not show any effect when applied to any part of the hyphae. The effect was similar to that of chitinase when both enzymes were applied to the hyphal tip [11]. Branching frequency in Acremonium sp. grown in batch culture may be shear-sensitive and branches more frequently as shear rate increases [12]. The synchrony of nuclear replication in individual and multinucleate hyphae of Aspergillus nidulans are reported. Protoplasmic organization of hyphal tips among fungi has been observed in vesicles and spitzenkörper.

The spitzenkörper is found in elongating hyphal tip of higher fungi. In this study, a possible relation between process of cell cycle and branching was studied by testing the effect of a nuclei distribution, mutation, cell cycle inhibitors, and conditional cell cycle mutations in combination with tipgrowth inhibitors and varying substrate concentrations on branch initiation. Formation of branches was blocked after inhibition of nuclear division, which was not caused by a reduced growth rate [13]. The hyphal length of Penicillium chrysogenum during penicillin synthesis decreased at high agitation rate. Hyphal fragmentation occurred probably by both shaving-off the external clump hyphae and breakage of free hyphae. On the contrary, long and ramified hypha possess more interaction with substrate, causing higher enzyme yield [14]. Using a population model, the morphological data were analyzed in the literature. It appears that the fragmentation is the dominant process in fed-batch fermentations (Table 1).

\section{Pellets}

The effect of fungal pellet size on the high yield of destruxin B by Metarhizium anisopliae led to a pellet of $2 \mathrm{~mm}$ diameter being the most suitable size for higher yield [15]. The influence of metal ions on pellet morphology and polygalacturonase synthesis by Aspergillus niger have been reported by Couri et al. [16]. The influence of modifications of the environmental conditions is observed on the growth of $A$. niger in terms of hyphal morphological patterns in pellets. A comparative study of the results obtained from shake-flask and bioreactor cultures showed that the intra- and extracellular catalase production was related neither to the fungal biomass nor to the size of the pellet. However, this production may be directly related to the external layer of the pellet and precisely to the morphology of the hyphae in this region [17]. The effect of the application of a pulsing flow to fluidized-bed bioreactors to control pellet morphology of $A$. niger and Phanerochaete chrysosporium are available in the literature [18]. In fermentation by periodical bleed feed operation, the decreased yield is most significant as biomass morphology changes from filamentous to pellet form [19]. The best maintenance of biotransformation capacity of pellets for a given media composition and cultivation conditions needs attention. During the change in morphology, when fluffy loose pellets were formed, the antibiotic production was high. This is contradictory to pectinase production [20]. The pellet morphology depends on inoculum level, genetic factors, medium composition, presence of surfactants, shear forces etc.

Studies on actinomycetes and fungi showed that the mass transfer, oxygen, nitrogen, phosphate limitations, and shear stresses are important process parameters during biosynthesis [21]. The control and regulation of hyphal growth and pellet size are of great importance [22]. Hence, a few important variables are referred here.

\section{Important Process Parameters}

\section{Dissolved Oxygen}

To study the effects of dissolved oxygen tension (DOT) on the morphology and growth kinetics of A. nidulans, a continuous-flow cultures has been used. In glucose limited continuous-flow cultures of $A$. nidulans, the mean length of hyphal segments and the degree of branching were reported to be independent of the DOT [23]. Study on the effect of low oxygen concentrations on growth and $\alpha$-amylase production of Aspergillus oryzae in model solid state fermentations systems was reported by Rahardjo et al. [24]. During on-line rheology measurements and control in fungal fermentations, the viscosity of the broth was controlled by dilutions alone or dilutions in combination with growth control. Factors influencing the rheological properties of broth are biomass concentration, specific growth rate, mixing qualities (impeller speed and working volume), and the dissolved oxygen concentration [23]. Intensive agitation has altered the morphology of Penicillium janthinellum and an increase in oxygen concentration decreases activity of xylanase [25]. Pecinase from Aspergillus sojae and viscosity are higher at higher DOT with increased number of small-sized pellets [20].

\section{Effect of Medium Composition}

New versions of Monod-type growth relations were used in the morphometric evaluation of the specific growth rate of A. niger grown on agar plates at high glucose levels [26]. A qualitative method is available for comparative study between agar plate and solid-state culture to understand their physiological differences [26]. Studies in conventional batch culture have confirmed that the initial glucose concentration in the fermentation medium affects citric acid production by A. niger and the fungal morphology [27]. Time profiles of morphological parameters, viz., mean perimeter of clump, mean length of filament, mean diameter of filaments, and mean diameter of vacuoles, have been used to establish a relationship between vacuolation, fragmentation, and product formation under various agitation conditions and glucose levels [27]. The influence of carbon source and aeration rate on red pigment production in Paecilomyces sinclairii has been characterized with the aid of mycelial morphology and broth rheology [28]. The mycelial morphology of the Ashbya gossypii culture with mineral support is different from that of the cultures without support, which enables the accumulation of intracellular riboflavin. In the presence of mineral support, mycelia may be stable and the riboflavin production period may be extended [29]. 
Enzyme activity and fungal morphology were investigated using various concentrations of phosphate for the production of xylanase by Aspergillus awamori on synthetic medium in shake-flask cultures. Mycelia and small pellets produce higher enzyme productivity than large pellets.

\section{Effect of Elicitors}

The effects of elicitors on $P$. chrysogenum morphology was established with the help of image analysis. A considerable increase in spore numbers was observed in all mannan oligosaccharide-supplemented stirred-tank reactor cultures. When oligosaccharide elicitors have been added to liquid cultures of $P$. chrysogenum, an increase in tip numbers and clump size was observed. Probable understanding of the mechanism of elicitation will facilitate further application in different bio-industries [30].

\section{Effect of $\mathrm{pH}$}

The assessment of microbody luminal $\mathrm{pH}$ (between 7 and 7.5 ) in $P$. chrysogenum is compatible with the enzymes localized in organelles involved in penicillin biosynthesis [31]. Pilot-scale studies were performed to determine the impact of dissolved oxygen, temperature, $\mathrm{pH}$, and carbon dioxide on the process for the scale-up of fungal fermentation for the production of pneumocandins. The effect of substrate $\mathrm{pH}$ determines the growth rate of the fungus and proliferation of the fungus in medium. This gives vital information for determining the subculture frequency and for designing substrate parameters for nursery/plantation programs [32].

\section{Effect of Agitation Intensity}

Qualitative relationship between agitation levels and medium viscosity has been observed in phytase production and A. niger morphology in submerged and solid-state cultures. Fungal morphology was greatly influenced by agitation with the morphological forms of small pellets and entangled mycelia predominating at low agitation, while the free filamentous form was obtained at $300 \mathrm{rpm}$. The morphological change in pellets is a good indicator for identifying the cell activity for exo-biopolymer production under agitated conditions [10].

Much information is available on mean projected area, mean total hyphal length, number of tips, mean total length, and many facets of hyphal morphogenesis, but precise understanding of the structural, biochemical, and genetic basis of apical growth remain unanswered so far. There is no correlation between agitation intensity on mycelial morphology and recombinant protein production in chemostat and fedbatch cultures. The dependence of mycelial morphology on type of impeller (Rushton-type impellers and pipe spargers) and agitation intensity has been observed in a chemostat culture of A. oryzae (Table 1). The mechanical properties of the filamentous fungi cell wall increased during the deceleration phase and resulted in higher resistance of the mycelia in the shear-dominant environment in the bioreactor. Higher agitation rates increase the oxygen transfer rate and bulk mixing without significant mechanical damage or loss of enzyme productivity. The mean convex perimeter of clumps should be within the threshold value to achieve increased production. The fragmentation of filamentous fungal hyphae depends on two phenomena: hydrodynamic stresses leading to hyphal breakage and hyphal tensile strength for resisting breakage. Agitation induced mycelial fragmentation of $A$. oryzae have been studied considering morphological (equivalent hyphal length) and hydrodynamic variables (specific power input and kinematic viscocity). Turbulent hydrodynamic theory was used for developing correlations (Table 1) that allowed experimental data of morphology and hydrodynamics to be used to estimate relative tensile strength of filamentous fungi.

The overall economic decision on the use of correct forms of morphology may be constrained by the design of the fermenters [33]. Studies clearly demonstrate that morphology is an important factor in determining the overall performance of citric acid production processes [34]. A special bioreactor design is required to provide mycelial and other producers sensitive to deformation forces with mixed cultivation conditions. Axial mixing systems are promising in this context. This can be a tool for scale-up and scaledown in geometrically dissimilar systems [35].

The relation between morphological parameters and specific growth rate of organism is established for specific bioreactions [24]. The study was used to assess filamentous fungal morphology and fragmentation behavior in largescale fedbatch fungal fermentations. To accomplish this, large-scale A. oryzae fermentations used for the production of a recombinant enzyme were carried out at two different impeller power levels. The efficient production of lactic acid by the filamentous fungus Rhizopus arrhizus in a stirred tank reactor requires a floating biomass with filamentous or pellet morphology [19].

Optimal conditions required for the mycelial growth of Aspergillus cinnamonea in a submerged shake flask cultures were determined to understand the relationship between parameters involved in enzyme production and fungal morphology and their dependence on cultivation conditions [36].

\section{MODELING IN FUNGAL MORPHOLOGY}

A mathematical model for apical growth, septation, and branching of mycelial microorganisms consists of two parts: the deterministic (hyphal tip growth and septation) and the stochastic (mycelial branching, direction of tip growth). These models describe morphological development of mycelia up to the formation of pellets. Two mathematical models presented simulation of the single microbial pellet growth of $P$. chrysogenum [37]. Various empirical correlations (Table 1) from a single-hyphal model were employed to accomplish the highest possible correspondence to the layer model. Three-dimensional growth of a fungus has been simulated, based on a model for the evolution of microscopic morphology of Trichoderma reesei. From this simulation, it is possible to extend a model describing the kinetics of hyphal extension and stochastic branching to three dimensions. This model could be used to simulate the formation of a pellet from one or more spores [38]. A population model has been used to analyze single hyphal growth and fragmentation in submerged cultures. To find the solutions for population models, Monte Carlo simulation is compared with a discretization method and is observed to be faster than the Monte Carlo simulation method. A number of measurements of total hyphal length and the number of tips revealed that it is possible to distinguish the four models used in the analysis ( cf. Table 2). Penicillium camembertii cultivated on a solid 
Table 2. Models for Mycelial Morphology

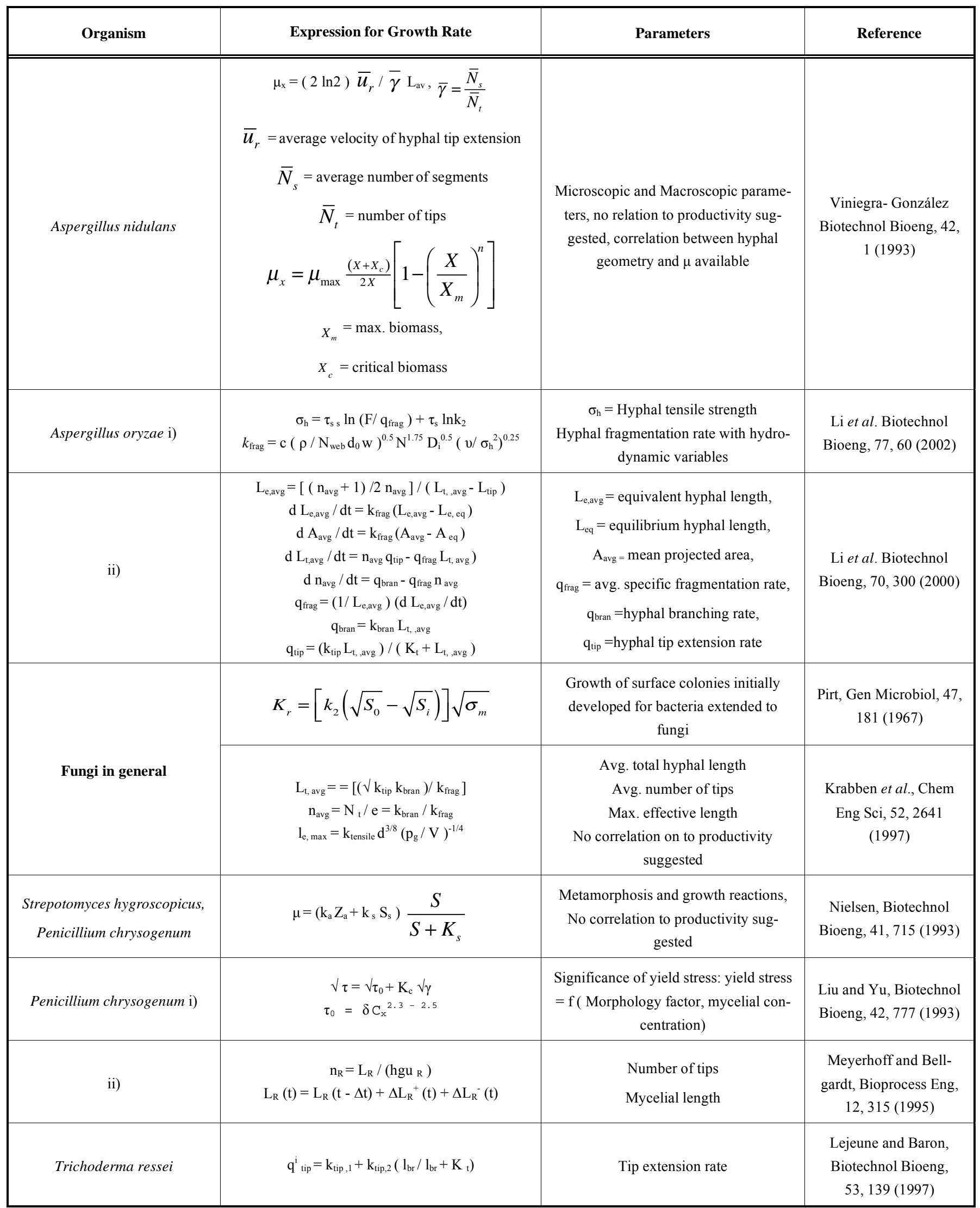


medium has been analyzed for growth kinetics. The Verlhust or logistic model was tested and validated for fitting the substrate consumption (lactate and peptone), ammonia production, and proton transfer kinetics. The model is useful to analyze growth because it allows the characterization at the end of exponential phase and in the beginning of stationary phase [39]. Advances have been made in both empirical and mechanistic types of kinetic models. An insight of various kinetic and intraparticle phenomena represent within the system. Factors on modeling, basic kinetic equations, effect of environmental conditions on growth, death kinetics, and intraparticle phenomena in solid state fermentation have been reported by Mitchell et al. [40].

Gierz and Bartinicki-Garcia [41] described a three-dimensional model of fungal morphogenesis based on the vesicle supply center concept. The 'neighbour-sensing' model brings together the basic essentials of hyphal growth kinetics into a vector-based mathematical model in which the growth vector of each virtual hyphal tip was calculated by reference to the surrounding virtual mycelium. This model can simulate growth on semisolid substrata like agar or soil, which enables realistic simulation of mycelial colonies of filamentous fungi grown on Petri-dish-style experimental conditions. The biomechanical models of hyphal growth in actinomycetes were investigated. This model exhibits realistic hyphal shapes and indicates a self-similar tip growth mechanism consistent with that observed experimentally [42]. A population- based morphologically structured model for hyphal growth and product formation in streptomycin fermentation was successfully applied to batch fermentation process [43].

However, a relationship between the morphology and productivity is a complex phenomenon involving mass transport, molecular basis of morphological analysis, and flow behavior in mycelial structure [6].

A new technique based on a fractal model has been developed to quantify the macroscopic morphology of mycelia. Studies show that the mycelial mass in the bioreactors can be treated as a fractal structure, with its fractal dimension being a quantitative morphological index [44]. To understand the generation of various colony patterns of filamentous fungi, a colony model with single- and multi-mycelial layers that originated by consuming a limited amount of nutrient was developed [45]. A model for branch initiation in A. nidulans is used to measure growth parameters. Kim et al. [46] reported the kinetic model to describe the morphological differentiation and the celphalosporin C produced from Cephalosporium acremonium. The proposed model is based on the total cell mass consisting of hyphae. Swollen hyphal fragments and arthrospores can only produce celphalosporin C. Some approximation has been made by considering total cell mass to correlate with antibiotics production [47].

\section{CONCLUSIONS}

Powerful methods to characterize and estimate morphological parameters have generated important data. However, correlation of physical parameters (viz., rheology, agitation intensity, dissolved oxygen level, $\mathrm{pH}$, and temperature) of biological reaction media, cell mass, morphology, and productivity is yet to be developed to obtain a moderately simple model based on a sound mechanistic background with proper physiology of morphogenesis of filamentous organism. The highly structured model of Megee et al. [48] using 44 parameters cannot be experimentally validated so far [49]. At present, it is difficult to obtain a direct link between morphology and productivity. However, different models developed for fungal morphology can be modified and manipulated to explain the experimental methods to a large extent. One might consider with present-day knowledge of quantitative morphology to improve the performance of the bioreactor.

\section{REFERENCES}

[1] El-Sabbagh N, McNeil B, Harvey LM. Dissolved carbondioxide effects on growth, nutrient consumption, penicillin synthesis and morphology in batch cultures of Penicillium chryosogenium. Enzyme Mirobial Technol 2006; 39: 185-90.

[2] Znidařsič $\mathrm{P}$, Pavko A. The morphology of filamentous fungi in submerged cultivations as a bioprocess parameter. Food Technol Biotechnol 2001; 39: 237-52.

[3] Wang L, Ridgway D, Gu T, Murray M-Y. Effects of process parameters on heterologous protein production in Aspergillus niger fermentation. J Chem Technol Biotechnol 2003; 78: 1259-66.

[4] Pappagianni M. Fungal morphology and metabolite production in submerged mycelial processes. Biotechnol Adv 2004; 22: 189-259.

[5] Wang L, Ridgway D, Gu T, Moo-Young M. Bioprocessing strategies to improve heterologous protein production in filamentous fungal fermentations. Biotechnol Adv 2005; 23: 115-29.

[6] Grimm LH, Kelly S, Krull R, Hempel DC. Morphology and productivity of filamentous fungi. Appl Microbiol Biotechnol 2005; 69: 375-84.

[7] Pamboukian CRD, Facciotti MCR. Rheological and morphological characterization of Streptomyces olindensis growing in batch and fed-batch fermentations. Braz J Chem Eng 2005; 22: 31-40.

[8] Malagnae F, Silar P. Non-Mendelian determinants of morphology in fungi. Curr Opinion Microbiol 2003; 6: 641-45.

[9] Selbman L, Stingele F, Petruccioli M. Exoploysaccharide production by filamentous fungi: the example of Botryosphaeria rhodina. Antonie van Leeuwenhoek 2003; 84: 135-45.

[10] Park EY, Hamanaka T, Higashiyama, Fujikawa S. Monitoring of morphological development of the arachidonic-acid-producing filamentous microorganism Mortierella alpina. Appl Microbiol Biotechnol 2002; 59: 706-12.

[11] Vieheilig H, Alt-Hug M, Wiemken A, Boller T. Hyphal in vitro growth of the arbuscular mycorrhizal fungus Gloumus mosseae is affected by chitinase but not by $\beta$-1,3-glucanase. Mycorrhiza 2001; 11: 279-82.

[12] Jayus McDougall BM, Seviour RJ. Factors affecting the synthesis of (1-3) and (1-6)- $\beta$-glucanases by the fungus Acremonium sp. IMI383068 grown in batch culture. Enzyme Microbial Technol 2002; 31: 289-99.

[13] Dynesen1 J, Nielsen J. Branching is coordinated with mitosis in growing hyphae of Aspergillus nidulans. Fungal Genetics Biol 2003; 40:15-24.

[14] Nicolas-Santiago SD, Regalado-Gonzalez C, Garcia-Almendárez B, Fernández FJ, Téllez-Jurado A, Huerta-Ochoa S. Physiological, morphological, and mannanase production studies on Aspergillus niger UAM-GS1 mutants. Elec J Biotechnol 2006; 9: 50-60.

[15] Feng K-C, Rou T-M, Liu B-L, Tzeng Y-M, Chang Y-N. Effect of fungal pellet size on the high yield production of destruxin $\mathrm{b}$ by Metarhizium anisopliae. Enzyme Microbial Technol 2004 ; 34: 2225.

[16] Couri S, Pinto GAS, de Senna LF, Martelli HL. Influence of metal ions on pellet morphology and polygalacturonase synthesis by Aspergillus niger 3T5B8. Braz J Microbiol 2003; 34: 16-21.

[17] Kacerm-Chaouche N, Maraihi Z, Destain J, Thonart P. Study of catalase production by an Aspergillus phoenicis mutant strain in date flour extract submerged cultures. Biotechnol Agron Soc Environ 2005; 9: 173-78.

[18] Moreira MT, Sanroman A, Feijoo G, Lema JM. Control of pellet morphology of filamentous fungi in fluidized bed bioreactors by means of a pulsing flow. Application to Aspergillus niger and 
Phanerochaete chrysosporium. Enzyme Microb Technol 1996; 19: 261-66.

[19] Martak J, Schlosser S, Sabolova E, Kristofıkova L, Rosenberg M. Fermentation of lactic acid with Rhizopus arrhizus in a stirred tank reactor with a periodical bleed and feed operation. Process Biochem 2003; 38: 1573-83.

[20] Oncu S, Unluturk S, Tari C, Gogus N. Various parameters affecting pellet morphology, broth rheology and pectinase enzyme production in submerged fermentation in Aspergillus sojae. IUFOST 2006; 1215-26.

[21] Katzer W, Blackburn M, Charman K, Martin S, Penn J, Wrigley S. Scale-up of filamentous organisms from tubes and shake-flasks into stirred vessels. Biochem Eng J 2001; 7: 127-34.

[22] Du L-X, Jia S-J, Lu F-P. Morphological changes of Rhizopus chinesis 12 in submerged culture and its relationship with antibiotic production. Process Biochem 2003; 38: 1643-46.

[23] Carter BLA, Bull AT. The effect of oxygen tension in the medium on the morphology and growth kinetics of Aspergillus nidulans. $\mathrm{J}$ Gen Microbiol 1971; 65: 265-73.

[24] Rahardjo YSP, Sie S, Weber FJ, Tramper J, Rinzema, A. Effect of low oxygen concentrations on growth and $\alpha$-amylase production of Aspergillus oryzae in model solid-state fermentation systems. Biomol Eng 2005; 21: 163-72.

[25] Piccoli-Valle RH, Passos FJV, Brandi IV, Peternelli LA, Silva DO. Influence of different mixing and aeration regime on pectin lyase production by Penicillium griseoroseum. Process Biochem 2003; 38: 849-54.

[26] Larralde-Corona PC, Lopez- Isunza F, Viniegra-Gonzalez G. Morphometric evaluation of the specific growth rate of Aspergillus niger grown in agar plate at high glucose levels. Biotechnol Bioeng 1997; 56: 287-94.

[27] Pappagianni M, Mattey M, Kristiansen B. The influence of glucose concentration on citric acid production and morphology of Aspergillus niger in batch and culture. Enzyme Microb Technol 1999; 25: 710-17.

[28] Cho YJ, Hwang HJ, Kim SW, Song CH, Yun JW. Effect of carbon source and aeration rate on broth rheology and fungal morphology during red pigment production by Paecilomyces sinclairii in a batch bioreactor. J Biotechnol 2002; 95: 13-23.

[29] Lim SH, Ming H, Park EY, Choi JS . Improvement of riboflavin production using mineral support in the culture of Ashbya gossypii. Food Technol Biotechnol 2003; 41:137-44.

[30] Radman R, Bucke C, Keshavarz T. Elicitor effects on Penicillium chrysogenum morphology in submerged cultures. Biotechnol Appl Biochem 2004; 40: 229-33.

[31] vander Lende TR, Breeuwer P, Abee T, Konings WN, Driessen AJM. Assessment of the microbody luminal $\mathrm{pH}$ in the filamentous fungus Penicillium chrysogenum. Biochim Biophys Acta 2002; 1589: 104-11.

[32] Sundari SK, Adholeya A. Growth profile of ectomycorrhizal fungal mycelium: emphasis on substrate $\mathrm{pH}$ influence. Antonie van Leeuwenhoek 2003; 83: 209 -14.

[33] Pazouki M, Panda T. Understanding the morphology of fungi. Bioproc Eng 2000; 22: 127-43.
[34] Sankpal NV, Joshi AP, Kulkarni BD. Citric acid production by Aspergillus niger immobilized on cellulose microfibrils: Influence of morphology and fermenter conditions on productivity. Process Biochem 2001; 36: 1129-13.

[35] Priede MA, Vanags JJ, Viesturs UE. Performance of Aspergillus niger cultivation in geometrically dissimilar bioreactors evaluated on the basis of morphological analyses. Food Technol Biotechnol 2002; 40: 57-66.

[36] Yang F-C, Huang H-C, Yang M-J. The influence of environment conditions on the mycelial growth of Antrodia cinnamomea in submerged cultures. Enzyme Microbiol Technol 2003; 33: 395402.

[37] Meyerhoff J, Bellgardt K-H. Two mathematical models for the development of a single microbial pellet, Part II: Simulation of the pellet growth of Penicillium chrysogenum by a fast method equivivalent to a morphological detailed description. Bioproc Eng 1995; 12: 315-22.

[38] Lejeune R, Baron GV. Simulation of growth of a filamentous fungus in 3 dimensions. Biotechnol Bioeng 1997; 53: 139-50.

[39] Aldarf M, Fourcade F, Amrane A, Prigent Y. Growth model of Penicillium camembertii cultivated on a solid medium - A logistic model for substrate consumption and metabolite production. Process Biochem 2002; 38: 333-42.

[40] Mitchell DA, von Meien OF, Krieger N, Dalsenter FDH. A review of recent developments in modeling of microbial growth kinetics and intraparticle phenomena in solid-state fermentation. Biochem Eng J 2004; 17: 15-26.

[41] Gierz G, Barticki-Garcia S. A three-dimensional model of fungal morphogenesis based on the vesicle supply center concept. J Theor Biol 2001; 208: 151-64.

[42] Goriely A, Tabor M. Biomechanical models of hyphal growth in actinomycetes. J Theor Biol 2003; 222: 211-8.

[43] Liu G, Xing M, Han Q. A population-based morphologically structured model for hyphal growth and product formation in streptomycin fermentation. World J Microbiol Biotechnol 2005; 21: 132938.

[44] Patankar DB, Liu T, Oolman T. A fractal model for the characterization of mycelial morphology. Biotechnol Bioeng 1993; 42: 57178

[45] Matsuura S. Random growth of fungal colony model on diffusive and non-diffusive media. Forma 2000; 15: 309-19.

[46] Kim JH, Lim JS, Kim CH, Kim SW. Morphology and kinetics studies on cephalosporin $\mathrm{C}$ production by Cephalosporium acremonium M25 in a 30-1 bioreactor using a mixture of inocula. Lett Appl Microbiol 2005; 40: 307-11.

[47] O’Mahonya R, Basseta C, Holtona J, Vairab D, Roitta I. Comparison of image analysis software packages in the assessment of adhesion of microorganisms to mucosalepithelium using confocal laser scanning microscopy. J Microbiol Methods 2005; 61: 105-26.

[48] Megee RD, Kinoshita S, Fredrickson AG, Tsuchiya HM. Differentiation and product formation in molds. Biotechnol Bioeng 1970; 12: $771-801$

[49] Thilakavathi M, Basak T, Panda T. Modeling of enzyme production kinetics. Appl Microbiol Biotechnol 2007; 73: 991-1007.

This is an open access article licensed under the terms of the Creative Commons Attribution Non-Commercial License (http://creativecommons.org/licenses/ by-nc/3.0/) which permits unrestricted, non-commercial use, distribution and reproduction in any medium, provided the work is properly cited. 